\title{
ANNOUNCEMENT
}

\section{BEIJING SATELLITE SYMPOSIUM OF THE EIGHTH INTERNATIONAL CONGRESS OF BIORHEOLOGY}

\author{
August 11-13, 1992, Beijing, China
}

\section{Sponsorship}

The Chinese Society of Theoretical and Applied Mechanics

The Chinese Society of Biomedical Engineering

The Biophysical Society of China

\section{Scientific Programme}

Contributions on all aspects of biorheology are welcomed. The symposium will mainly consist of oral presentations. All abstracts submitted will be reviewed by the Programme Committee. Authors will be notified of the acceptance of their contribution by May 1st, 1992.

\section{Abstracts}

Participants who wish to present a communication are requested to send abstracts to the Executive Secretariat before March 1st, 1992. The abstracts should consist of two parts:

1. A short abstract should be made camera-ready in English on white bond paper with typing area of $165 \times 118 \mathrm{~mm}^{2}$ (width $\times$ height). The abstracts will be published in the journal of BIORHEOLOGY. Sample of typing format will be sent to the participants.

2. An extended-abstract in English on white bond paper of $210 \times 297 \mathrm{~mm}^{2}$ (A4) with a typing area of $145 \times 210 \mathrm{~mm}^{2}$ is requested. This abstract must be limited within 4 pages. The extended-abstracts will be collected in the Proceedings of the symposium. It will be distributed to all the participants at the symposium. This abstract will not interfere with further publication of the same content as a paper for any scientific journals.

\section{Accommodation}

Pleasant, reasonably priced accommodation will be available to symposium participants.

Single: US \$ 45-55 per night

Double: US \$25-30 per night

\section{Rigistration Fee}

\begin{tabular}{|c|c|c|}
\hline per person & $\begin{array}{c}\text { on } / \text { before } \\
\text { June } 1,1992\end{array}$ & $\begin{array}{c}\text { after } \\
\text { June } 1,1992\end{array}$ \\
\hline Delegate $^{(}$ & US $\$ 250$ & US $\$ 300$ \\
\hline Accompanying $^{(2)}$ & US $\$ 110$ & US $\$ 150$ \\
\hline Student $^{(}$ & US $\$ 110$ & US $\$ 150$ \\
\hline
\end{tabular}


(1) Covering a Proceedings, the welcoming party, the banquet, lunches during the symposium, a one day tour as well as entry to all scientific programs.

(2) Covering the welcoming party, the banquet and the one day tour.

(3) Covering a Proceedings, the welcoming party, lunches during the symposium as well as entry to all scientific programs.

Accompanying Person's Programme

\begin{tabular}{|c|c|c|c|}
\hline Date & Morning & Afternon & Charge \\
\hline 11th & Temple of Heaven & $\begin{array}{c}\text { 1. Tian An Men Square } \\
\text { 2. The Great Bell } \\
\text { Temple }\end{array}$ & US $\$ 30$ \\
\hline 12 th & Palace Museum & Beihai Park & US $\$ 40$ \\
\hline 13 th & $\begin{array}{c}\text { 1. Lama Temple } \\
\text { 2. White Peacock } \\
\text { of Art World }\end{array}$ & Friendship Store & US $\$ 30$ \\
\hline
\end{tabular}

\section{Post-symposium Tours}

Three optional post-s;mposium tour packages arranged by the China Golden Bridge Travel Service Corporation are available.

The packages are as follows:

1. Beijing-Nanjing-Shanghai-Hangzhou-Wuxi-Shanghai (8 days)

2. Beijing-Taian-Qufu-Ji'nan-Shanghai-Xi'an-Guilin (11 days)

3. Beijing-Taian-Qufu-Ji'nan-Shanghai (8 days)

4. Beijing-Chengdu-Lhasa-Chengdu-Guangzhou (8 days)

\section{Correspondence}

Dr. He Lin

The Chinese Society of Theoretical and Applied Mechanics

No.15, Zhong Guan Cun Road

Beijing, 100080, China

Telex: 222554 MEHAS CN

Fax: (86-1) 2561284

Tel: 2559588 